\title{
Incidence of Groundnut Rosette Disease (GRD) and Genetic Diversity of Groundnut Rosette Assistor Virus (GRAV) in Western Kenya
}

\author{
Benard Mukoye ${ }^{1,3, *}$, Millicent Florence Owuor Ndonga ${ }^{1}$, Hassan Karakacha Were ${ }^{2}$ \\ ${ }^{1}$ Department of Biological Sciences, School of Natural Sciences, Masinde Muliro University of Science and Technology (MMUST), \\ Kakamega, Kenya \\ ${ }^{2}$ Department of Agriculture and Land Use Management (ALUM), School of Agriculture, Veterinary Science and Technology, Masinde \\ Muliro University of Science and Technology (MMUST), Kakamega, Kenya \\ ${ }^{3}$ Department of Biosafety and Phytosanitary Services, Kenya Plant Health Inspectorate Service (KEPHIS), Nairobi, Kenya
}

Email address:

btemukoye@gmail.com (B. Mukoye), mndonga@mmust.ac.ke (M. F. O. Ndonga), hwere@mmust.ac.ke (H. K. Were)

${ }^{*}$ Corresponding author

\section{To cite this article:}

Benard Mukoye, Millicent Florence Owuor Ndonga, Hassan Karakacha Were. Incidence of Groundnut Rosette Disease (GRD) and Genetic Diversity of Groundnut Rosette Assistor Virus (GRAV) in Western Kenya. International Journal of Genetics and Genomics.

Vol. 7, No. 4, 2019, pp. 98-102. doi: 10.11648/j.ijgg.20190704.12

Received: September 11, 2019; Accepted: October 4, 2019; Published: October 16, 2019

\begin{abstract}
This study determined the incidence of groundnut rosette disease (GRD) and genetic diversity of groundnut rosette assistor virus (GRAV, genus Luteovirus) in western Kenya. The diseases is a major constraint of groundnuts in SubSaharan Africa (SSA) causing up to $100 \%$ yield losses in severe cases. Among the GRD associated viruses, GRAV plays a crucial role in vector transmission of the other viruses. Therefore understanding the genetics of GRAV across SSA could enhance development of resistance to the disease. In Kenya, groundnuts are mainly grown in western region, however, the yields are poor mainly due to GRD. Information on occurrence and distribution of GRD in western Kenya was not documented and little was known about the characteristics of associated viruses. Two diagnostic surveys were conducted in six counties; Bungoma, Busia, Homabay, Kakamega, Siaya and Vihiga. Symptomatic and asymptomatic groundnut were collected in RNAlater ${ }^{\circledR}$ solution for laboratory analysis. Total RNA was extracted from the leaf samples using RNeasy Mini Kit (Qiagen) according to the manufacturers' protocol and used for double stranded cDNA synthesis using the SuperScript II kit. The cDNA was column-purified with the DNA Clean \& ConcentratorTM-5 - DNA kit. The samples were then processed with the transposon-based chemistry library preparation kit (Nextera XT, Illumina) following manufacturer's instructions. The fragment sizes structure of the DNA libraries was assessed using the Agilent 2100 Bioanalyzer. The indexed denatured DNA libraries were sequenced (200-bp paired-end sequencing) on the Illumina MiSeq platform (Illumina). Reads quality check was done using FastQC. Trimmed reads were used for de novo assembly and contigs aligned to the viral genomes database using CLC Genomics Workbench 10.1.2. The assembled contigs were subjected to a BLASTn search against the GenBank database. Phylogenetic analyses and comparisons were performed using the MEGA X. Average incidence was $53 \%$ and $41 \%$ in the short and long rain seasons, respectively. Chlorotic rosette was the dominant symptom followed by Green rosette and Mosaic. The GRAV coat protein (GRAV-CP) gene sequences revealed $97-100 \%$ identity with GeneBank isolates showing very slight variations across SSA. The study concludes that GRD incidence is high in western Kenya and that GRAV is highly conserved across SSA. The study recommends an urgent need to curb GRD, possibly through the exploitation of pathogen derived resistance (PDR) with GRAV as the suitable candidate.
\end{abstract}

Keywords: Incidence, GRAV, Kenya, Diversity 


\section{Introduction}

Groundnuts, (Arachis hypogaea L.), is the fifth most important annual oilseed and food legume crop. It is grown in diverse environments throughout the semi-arid and subtropical regions, in nearly 100 countries, in the six continents of the world [1]. Groundnut production is of great value in terms of income and nutrition for smallholder farmers in East Africa $[2,3]$. Resource poor smallholder farmers grow nearly $75-80 \%$ of the world's groundnuts in developing countries obtaining yields of $500-800 \mathrm{~kg} / \mathrm{ha}$, as opposed to the potential yield of $>2.5 \mathrm{t} / \mathrm{ha}$ [4]. In western Kenya, an average of $600-$ $700 \mathrm{~kg} / \mathrm{ha}$ is achieved which is less than $30-50 \%$ of the potential yield [2]. Low yields are mainly attributed to poor quality seeds, drought, poor agronomic practices, numerous pests and diseases caused by numerous pathogenic viruses, fungi, bacteria and nematodes [5, 3]. Among the viral diseases, Groundnut rosette disease (GRD) is the most devastating in Sub-Saharan Africa (SSA) causing an estimated annual loss of US\$156 million every year [6]. The disease is caused by association between Groundnut rosette assistor virus (GRAV), Groundnut rosette umbravirus (GRV) and a Satellite-RNA (Sat-RNA) of GRV [7]. To be transmitted by aphids, GRV and Sat-RNA are packaged within the GRAV coat protein [8].

Groundnut rosette assistor virus (GRAV) belongs to the family Luteoviridae [9]. The GRAV virion are isometric shaped with $28 \mathrm{~nm}$ diameter non-enveloped particles of polyhedral symmetry. It has a single stranded positive sense RNA non-segmented genome of 6900 nt that encodes both structural and non-structural proteins [10]. It is suggested that GRAV encodes six open reading frames (ORFs) just like other luteoviruses. The GRAV virions are composed of $24.5 \mathrm{kDa}$ single coat protein (CP) subunits. This virus is antigenetically related to Potato leaf roll virus, Beet western yellow virus and Bean/pea leaf roll virus [11].

Both chlorotic and green rosette symptoms occur throughout the SSA, and sometimes occur in the same field [12]. A less common third symptom variant, called mosaic rosette, resulting from mixed infection by the Sat-RNA causing chlorotic and green mottled variant, has been reported from East Africa [11, 6]. Infected groundnut leaves may also show symptoms other than the typical chlorotic or green rosette [8].

In Eastern Uganda, green rosette symptoms predominate [13]. This is in contrast with [14], who reported that chlorotic rosette symptoms of GRD have been the predominant form throughout SSA and western Kenya. The dynamics of the GRD virus symptomatology, therefore, needs constant monitoring. For example, in Nigeria, a there was shift from green to chlorotic rosette over a period of about 20 years. The shift could be due to changes in the genome sequences of GRD associated agents or other factors [13].

Survey conducted by [14] showed that GRD incidence ranged between $40 \%$ in areas of western Kenya surveyed in the groundnut growing seasons of 1997-1998 and Sat-RNA shared $89-95 \%$ nucleotide identity with those from Malawi and Nigeria. Since then, no other survey has been conducted to ascertain the current status of GRD in the region. In addition, no genomic sequences of any of the GRD associated viruses existed in the GeneBank from western Kenya. With the dynamics of the disease, this hinders proper diagnosis of GRD and development of management strategies. This study determined the incidence of GRD and assed the sequence diversity of GRAV of isolates from western Kenya.

\section{Materials and Methods}

\subsection{Field Survey}

The GRD diagnostic survey was conducted in all the major groundnut growing areas in western Kenya during the short rains (October to December 2016) and long rains season (May to July 2017). The following Counties were covered: Bungoma, Busia, Homabay, Kakamega, Siaya and Vihiga. Sampling of groundnut farms was done by stopping at regular predetermined intervals, of 3-8 km along motorable roads that traverses each sampling area. The survey were conducted, by walking through groundnut fields, and visually inspecting groundnut crops for symptomatic leaves. Disease incidence was calculated according to [15], as the percentage of plants showing GRD virus symptoms, to the total number of plants observed in the field. GRD viral incidence was scored using a rating scale according to [15], where: low incidence $=1-20 \%$; moderate incidence $=21-49 \%$ and high incidence $=50-100 \%$. The types of GRD symptoms observed were recorded. The collected data on GRD virus incidence and severity, was subjected to analysis of variance (ANOVA), using Statistical Analysis System (SAS) program version 9.3.1 software. Pairwise comparisons of means was done using Least Significance Differences (LSD) for multiple-means comparison method at $\mathrm{P} \leq 0.05$ confidence level.

Symptomatic and asymptomatic leaves were collected in $10 \mathrm{ml}$ falcon tubes containing RNAlater ${ }^{\circledR}$ RNA Stabilization Solution and put in a cool box. The samples were kept in the fridge and used for molecular studies. Geographical Positioning System (GPS) (entrex venture HC GARMIN ${ }^{\mathrm{TM}}$ ), was used to record the latitude, longitude and altitude of the sampled farms.

\subsection{RNA Extraction, Sequencing and Sequence Analyses}

Total RNA was extracted from the leaf samples using RNeasy Mini Kit (Qiagen) according to the manufacturers' protocol and used for double stranded cDNA synthesis using the SuperScript II (Thermo Fisher Scientific, Waltham, USA) kit. The cDNA was column-purified with the DNA Clean \& ConcentratorTM-5 - DNA kit (Zymo Research, Irvine, USA). The samples were then processed with the transposonbased chemistry library preparation kit (Nextera XT, Illumina) following manufacturer's instructions. The fragment sizes structure of the DNA libraries was assessed using the Agilent 2100 Bioanalyzer (Agilent Technologies, 
Santa Clara, USA). The indexed denatured DNA libraries were sequenced (200-bp paired-end sequencing) on the Illumina MiSeq platform (Illumina).

Reads quality check was done using FastQC (version 0.11.5). Reads were then trimmed to remove poor quality sequences. Trimmed reads [16] were used for de novo assembly and contigs aligned to the viral genomes database (ftp://ftp.ncbi.nih.gov/genomes/Viruses/all.fna.tar.gz/, downloaded on October 2017) using CLC Genomics Workbench 10.1.2. The assembled contigs were subjected to a BLASTn search against the GenBank database [17]. Complete and partial GRV Sat-RNA sequences used for comparison and phylogenetic analyses were retrieved from GenBank (http://www.ncbi.nlm.nih.gov/). Phylogenetic analyses and comparisons were performed using the MEGA $\mathrm{X}[18]$.

\section{Results}

\subsection{Incidence of GRD}

A total of 526 farms were sampled in six (6) counties (253 in long rain and 273 in short rain). The main symptoms observed in all Counties in order of abundance, starting from the most common, were chlorotic rosette, green rosette and mosaic. Generally, GRD incidence was high during the short rain season $(53 \%)$ than the long rain season $(41 \%)$ in all Counties. High mean GRD incidence was recorded in Kakamega in the short rain season $(68.92 \%)$ while moderate incidence was in Bungoma (30.89\%) during the long rain season. There was a significant difference in GRD incidence among the counties $(p=0.011)$. Siaya County had the overall lowest incidence which was significantly different from that of Kakamega but did not vary significantly from that of Bungoma, Busia, Vihiga and Homabay counties (Table 1).

Table 1. Mean GRD incidence (\%) per County.

\begin{tabular}{lllll}
\hline County & Season & N & Mean (\%) & $\begin{array}{l}\text { Std. Error of } \\
\text { Mean }(+/-)\end{array}$ \\
\hline \multirow{2}{*}{ Bungoma } & Long rain & 45 & 30.89 & 4.534 \\
& Short rain & 47 & 66.51 & 4.295 \\
Busia & Long rain & 74 & 43.36 & 3.526 \\
& Short rain & 108 & 46.56 & 2.728 \\
Homabay & Long rain & 73 & 48.60 & 3.919 \\
& Short rain & 55 & 48.22 & 4.025 \\
Kakamega & Long rain & 30 & 43.47 & 5.283 \\
& Short rain & 17 & 94.12 & 4.779 \\
Siaya & Long rain & 31 & 33.94 & 4.820 \\
Vihiga & Short rain & 26 & 43.23 & 6.645 \\
& Short rain & 20 & 47.50 & 6.412 \\
& Long rain & 253 & 41.51 & 1.962 \\
& Short rain & 273 & 53.04 & 1.909 \\
\hline
\end{tabular}

\subsection{Diversity of GRAV}

Four GRAV coat protein (CP) gene sequences were assembled (600 nt). The four were compared with GRAV CP gene sequences from Malawi, Nigeria and Ghana available in the GeneBank. The comparison revealed $97-100 \%$ identity with the Kenyan isolates. Isolates GRAV-5 and GRAV-19 each had 100\% identity with M16GCP (AF195824.1) and 99\% with M8GCP (AF195502.1) then 98\% with the other Malawian, Nigerian and Ghanaian Isolates. Isolate GRAV-22 had 99\% identity with isolates M16GCP and M8GCP then $98 \%$ with the other Malawian, Nigerian and Ghanaian Isolates. Isolate GRAV-12 had 100\% identity with M16GCP and $99 \%$ with M8GCP from Malawi, then 98\% with the rest of Malawian, Ghanaian and Nigerian isolates except N29GCP (AF195828.1) and N15GCP (AF195825.1) that showed 97\% identity. In phylogenetic tree, all Kenyan isolates clustered together with isolate M16GCP. In general all western Kenya isolates exhibited closest identity and grouped together with some Malawian isolates, M16GCP and M8GCP than the rest of Malawian, Nigerian and Ghanaian isolates (Figure 1).

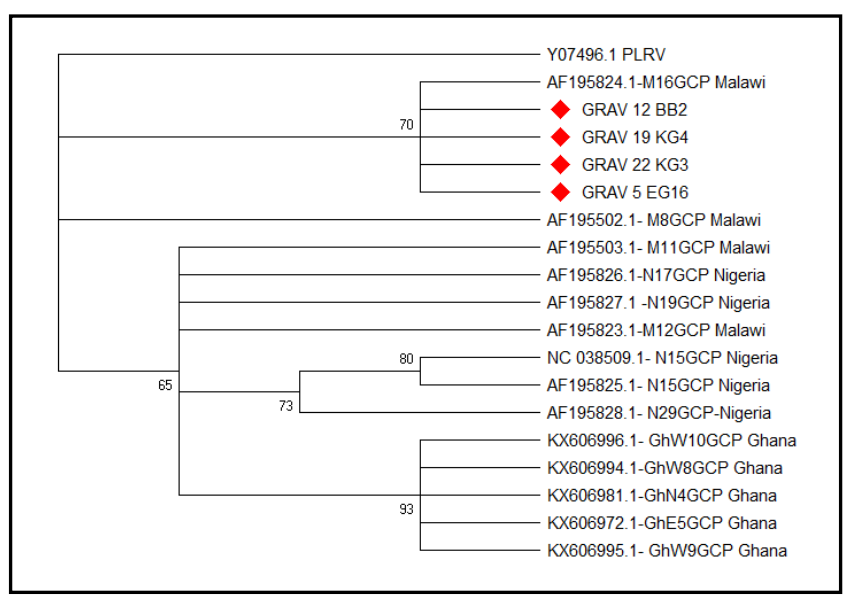

Figure 1. Phylogenetic tree of the 600nt western Kenya GRAV CP and GeneBank isolates.

The evolutionary history was inferred by using the Maximum Likelihood method based on the Kimura 2parameter model. The tree is rooted on of a distantly related Luteovirus (Potato leaf roll virus - Y07496.1 PLRV). Bootstrap confidence values (500 replications) are shown.

\section{Discussion}

Groundnut rosette is the most prevalent disease of groundnuts in western Kenya. The disease was recorded in every County that was surveyed with incidences of up to $100 \%$ at some farm levels. The short rain season recorded higher incidence $(53 \%)$ than the long rains $(41 \%)$. This could be attributed to the high vector pressure during the short rains as compared to the long rains season when the aphid pressure is low as a result of heavy rains that wash the insects away. A study by [12], found that periods of long rains negatively affected GRD progression as aphid vector pressure was low. [19], reported a positive correlation between potato disease incidence and aphid numbers. This further supports the implication that virus disease incidence variations between the seasons contributed to by differences in vector pressure. Incidence increased with increase in severity due to early infection leading to intensification of the viruses as the plant 
grows and build-up of inoculum for vectors to spread to nearby plants. Groundnut rosette is a polycyclic disease whereby diseased plants from previous cropping season serves as inoculum sources for initiating subsequent disease spread [8]. In western Kenya, groundnuts are grown in two cropping seasons (long rains and short rains) and due to limitation in land to practice shift cultivation, the same piece of land is continuously used to grow the same or related host crops in the subsequent cropping season. Therefore, GRD infected groundnuts and possibly hosts of any of the GRD associated viruses remaining from the long rains season serves as immediate sources of the GRD agents beginning the disease cycle at early stages of crop development in the short rains cropping season. Such initial infections that occur at early stages of plant growth enhance repeated cycles of infections thus increasing the severity of the disease in the groundnut fields [6].

All major GRD symptoms were observed in the surveyed region with chlorotic rosette being most prevalent followed by green rosette. This supports the findings of [14], who reported chlorotic rosette to be the most prevalent GRD symptoms in the region. The high prevalence of the chlorotic rosette could also be attributed to its higher transmission efficiency compared to green rosette. This observation concurs with that of [20], who reported minimum acquisition feeding periods of $4 \mathrm{~h}$ and $8 \mathrm{~h}$ for chlorotic and green rosette respectively and the median latent periods of $26.4 \mathrm{~h}, 38.4 \mathrm{~h}$ respectively, for chlorotic and green rosette. The mosaic symptom has not been previously reported but was distributed in most of the surveyed region. This suggests that there is evolution of new variants of Sat-RNA in western Kenya that might be causing these new symptoms or the mosaic was due to another causal agent. A total of 10 variants of Sat-RNA have been reported to be associated with the various GRD symptoms [21]. A mixture of either variants, especially the chlorotic and green rosette and/or the mild ones, are likely to induce the mosaic symptoms [8]. It is therefore possible that some of these variants occur in western Kenya in mixed infections, thus causing the varied symptom observed, especially the mosaic. Apart from the typical rosette symptoms, other symptoms including severe leaf curling and bunching were observed. This suggests that there is wider variability in expression of GRD and could be due to more severe variants of associated viruses or other agents. It is worth noting that from the Next generation Sequences (NGS) of this study, other than GRD associated viruses, other viruses were detected (data not shown) and could be the reason for some of the new symptoms observed on groundnuts [22].

The four GRAV CP gene sequences from western Kenya clustered together and had $97-100 \%$ identity with those from Malawi, Ghana and Nigeria implying that there was no much difference among the western Kenya GRAV CP gene isolates. Kenyan GRAV CP isolates exhibited closest identities with Malawian isolates than Nigerian and Ghanaian isolates. This findings concurs with [14] and [23], who observed closer identity between sequences from the same geographical region as compared to those from separate geographical regions. In the study, [14] found that Kenyan isolates of GRAV CP gene shared $98 \%$ nucleotide identity with Malawian isolates as compared to $96-97 \%$ with those from Nigeria. [23], observed that Ghanaian GRAV CP gene sequence isolates had $98-99 \%$ nucleotide identity as compared to $97-99 \%$ with Malawian isolates. Such differences due to geographical distances could be as a result of differences in environmental conditions that bring about variations in evolution of the viruses. All western Kenya GRAV CP isolates were closest to Malawian isolates M16GCP and M8GCP (99-100\%) than the other isolates from Malawi, Nigeria and Ghana. A similar observation was noted by [14], where two of the Kenya isolates in the study (K1 and K2), specifically from western Kenya were closest to M16GCP and M8GCP than with the rest of her isolates from other regions in Kenya. This could imply that the GRAV CP gene from western Kenya have not evolved for at least the last 20 years. However variation could exist in GRAV from other regions in Kenya. In general all GRAV CP gene sequences both in this study and those in GeneBank shared $97-100 \%$ nucleotide identity. This implies that GRAV $\mathrm{CP}$ gene is highly conserved across the wide geographical region in Sub-Saharan Africa. It can thus be targeted as a suitable candidate for development of pathogen-derived resistance (PDR) through genetic engineering that can be used across Sub-Saharan Africa [9, 23].

\section{Conclusion}

Groundnut Rosette (GRD) is still the major disease of groundnuts and is present whenever groundnuts are grown in western Kenya. Chlorotic rosette is the most prevalent form of symptom on groundnuts in western Kenya. The mosaic rosette is an emerging symptom in groundnuts and could be due to dual infection by Sat-RNA variants or other agents. The GRAV CP gene is less diverse even with wide geographical distance.

The four GRAV sequences were deposited in GeneBank with accession numbers LC480460 (GRAV 12), LC480461 (GRAV 22), LC480462 (GRAV 19) and LC480463 (GRAV 5).

\section{Acknowledgements}

This work was funded by The royal society of UK, The International Foundation for Science, The National Research Fund (NRF-Kenya) and the ILRI BecA hub. We are grateful to Dr. Wellington Ekaya and the entire BecA capacity building team for allowing this work to be done at the BecA labs.

\section{References}

[1] Kumar, P. L. \& Waliyar, F., (Ed). (2007). Diagnosis and detection of viruses infecting ICRISAT mandate crops: Methods Manual. Patancheru 502 324, Andhra Pradesh, India; International Crops Research Institute for the Semi-Arid Tropics. 133pp. 
[2] Kidula, N., Okoko, N., Bravo-Ureta, B. E., Thuo, M. \& Wasilwa, L. (2010). A preliminary analysis of yield differences in groundnuts between research and non-research farmers in Kenya. In paper presented at the $12^{\text {th }}$ KARI biennial scientific conference, 8-12 November 2010, Naiobi Kenya.

[3] Okello, D. K., Birima, M. \& Deom, C. M., (2010). Overview of groundnut research in Uganda: Post, present and future. Afr. J. Biotechnol. 9: 6448-6459.

[4] Kayondo, S. I., Rubaihayo, P. R., Ntare, B. R., Gibson, P. I., Edema, R., Ozimati, A. \& Okello, D. K. (2014). Genetics of resistance to groundnut rosette virus disease: African crop science journal, 22: 21-29. ISSN: 1021-9730/2014.

[5] Mutegi, C. K. (2010). The extend of aflatoxin and aspergillus section flavi, penicillium spp. and Rhizopus spp. contamination of peanuts from households in Western Kenya and the causative factors of contamination. PhD dissertation, University of Kwazulu-Natal, Pietermaritzburg. South Africa.

[6] Waliyar, F., Kumar, P. L., Ntare, B. R., Monyo, E., Nigam, S. N., Reddy, A. S., Osiru, M. \& Diallo, A. T. (2007). A Century of Research on Groundnut Rosette Disease and its Management. Information Bulletin no. 75. Patancheru 502 324, Andhra Pradesh, India. International Crops Research Institute for the Semi-Arid Tropics, 40 pp. ISBN 978-92-9066501-4.

[7] Taliansky, M. E. \& Robinson, D. J. (2003). Molecular Biology of umbraviruses: Phantom warriors. J. Gen. Virol. 84: 19511960.

[8] Naidu, R. A., Robinson, D. J., \& Kimmins, F. M. (1998a). Detection of each of the causal agents of groundnut rosette disease in plants and vector aphids by RT-PCR. J. Virol. Methods 76: 9-18.

[9] Deom, C. M., Naidu, R. A., Chiyembekeza, A. J., Ntare, B. R. \& Subrahmanyam, P. (2000). Sequence diversity with the three agents of groundnut rosette disease. Phytopathol. 90: 214-219. doi: 10.1094/PHYTO.2000.90.3.214

[10] Murant, A. F., \& Kumar, I. K. (1990). Different variants of the satellite RNA of groundnuts rosette virus are responsible for the chlorotic and green forms of groundnut rosette disease. Ann. Appl. Biol. 117: 85-92.

[11] Scott, K. P., Farmer, M. J., Robinson, D. J., Torrence, L. \& Murant, A. F. (1996). Comparison of the coat protein of groundnut rosette assistor virus with those of other luteovirus. Ann. Appl. Biol. 128: 77-83.

[12] Mugisa, I. O., Karungi, J., Akello, B., Ochwo-Ssemakula, M. K. N., Biruma, M., Okello, D. K. \& Otim, G. (2016). Determinants of groundnut rosette virus disease occurrence in Uganda. Elseviercropprotectionjournal.http://dx.doi.org/10.1016/j.crop ro.2015.10.019.

[13] Okello, D. V, Akello, L. B, Tukamuhabwa, P., Odongo, T. L,
Ochwo-Ssemakula, M., Adriko, J. \& Deom, C. M. (2014). Groundnut rosette disease symptom types, distribution and management of the disease in Uganda. African journal of plant science. 8: 153-163.

[14] Wangai, A. W., Pappu, S. S., Pappu, H. R., Okoko, N., Deom, C. M. \& Naidu, R. A. (2001). Distribution and characteristics of groundnut rosette disease in Kenya. Plant Disease, 85: 470474 .

[15] Reddy, D. V. R. (1991). Groundnut viruses and virus diseases; Distribution, identification and control. Rev. Plant Pathol. 70: 665-678.

[16] Haas B. J, Papanicolaou A, Yassour M, Grabherr M, Blood P. D, Bowden J, Couger M. B, Eccles D, Li B, Lieber M, MacManes M. D, Ott M, Orvis J, Pochet N, Strozzi F, Weeks N, Westerman R, William T, Dewey C. N, Henschel R, LeDuc R. D, Friedman N, Regev A. (2013). De novo transcript sequence reconstruction from RNA-seq using the Trinity platform for reference generation and analysis. Nat Protoc 8: 1494-1512. https://doi.org/10.1038/nprot.2013.084.

[17] Altschul, S. F., Gish, W., Miller, W., Myers, E. W. \& Lipman, D. J. (1990). Basic local alignment search tool. J Mol Biol 215: 403-410. https://doi.org/10.1016/S0022-2836(05)803602.

[18] Kumar, S., Stecher, G., Li M., Knyaz, C., \& Tamura, K. (2018). MEGA X: Molecular Evolutionary Genetics Analysis across computing platforms. Molecular Biology and Evolution 35: $1547-1549$.

[19] Were, H. K., Kabira, J. N., Kinyua, Z. M., Olubayo, F. M., Karinga, J. K., Aura, J., Lees, A. K., Cowan, G. H. \& Torrance, L. (2013). Occurrence and Distribution of Potato Pests and Diseases in Kenya. Potato Research 56: 325-342.

[20] Misari, S. M., Abraham, J. M., Demski J. W., Ansa, O. A., Kuhn, C. W, Casper, R. \& Breyel, E. (1988a). Aphid transmission of the viruses causing chlorotic and green rosette diseases of peanut in Nigeria. Plant Disease 72: 250-253.

[21] Blok, V. C., Ziegler, A., Robinson, D. J. \& Murant, A. F. (1994). Sequences of 10 variants of the satellite- like RNA -3 of groundnut rosette virus. Virology 202: 25-32.

[22] Mukoye, B., Mangeni, B. C., Sue, J., Ndonga, M. F. O., \& Were, H. K. (2018). Next Generation Sequencing as a tool in modern pest diagnosis. A case study of groundnuts (Arachis hypogaea) as a potential host of new viruses in western Kenya. Conference proceedings: The $2^{\text {nd }}$ Phytosanitary Conference, $4^{\text {th }}-8^{\text {th }}$ June, 2018 at KEPHIS-Nairobi, Kenya.

[23] Appiah, A. S., Sossah, L. F., Tegg, S. R., Offei, K. S. \& Wilson, R. C. (2017). Assessing sequence diversity of goundnut rosette disease agents and the distribution of groundnut rosette assistor virus in major groundnut-producing regions of Ghana. Trop. Plant Pathol. Doi: 10.1007/s40858017-0140-x. 